\title{
Student mental health and clinical education: exploring the DCE experience
}

\author{
Bridget R. Eubanks ${ }^{1 *}$, Chad Cook² and Katherine Myers ${ }^{2}$
}

\author{
'Doctor of Physical Therapy Program, College of Pharmacy and Health Sciences, Campbell University, Lillington, NC, USA; \\ 2Doctor of Physical Therapy Division, Department of Orthopaedic Surgery, Duke University School of Medicine, Durham, NC, USA
}

\section{Abstract}

Purpose: There is a potential link between the clinical education phase of a physical therapist's education and increased incidence of student mental health challenges. The Director of Clinical Education (DCE) has a complex role in supporting students and clinical sites during clinical education experiences (CEEs.) The purposes of this study were to explore DCE's experiences and perceptions with supporting students with mental health challenges during CEEs.

Methods: Two-hundred-twenty DCEs from accredited Doctor of Physical Therapy programs were invited to participate in an electronic survey. Survey questions included demographics, institutional and curricular characteristics, and current perceptions/ experiences with student mental health challenges. DCEs $(n=106 ; 48.2 \%)$ responded and were included in the analyses. Analyses included descriptive statistics, simple frequencies, and binary logistic regression. Incident coding processes analyzed responses of open-ended questions.

Results: Seventy-four percent of respondents indicated awareness of a student(s) experiencing a mental health concern during a full-time clinical experience in the past 3 years. Regression analyses showed that length of terminal clinical experience, out-ofstate placement, cohort size, and availability of online/video counseling were related to prevalence of DCE's experience. Forty-six percent of DCEs indicated feeling prepared to deal with these issues, while 35\% were 'unsure'. DCEs indicated experience, training, and workload support as contributors to successfully supporting students.

Conclusion: Results contribute to the emerging understanding of the prevalence of student mental health challenges in physical therapist education from the DCE's perspective. Our findings suggest that institutional and curricular characteristics are potential contributors to the prevalence of this issue. We recommend training and institutional support for the DCE in these situations.

Keywords: Director of Clinical Education; education

MeSH terms: clinical education; physical therapist; mental health

Received: 24 March 2020; Revised: 12 February 2021; Accepted: 20 May 202 I; Published: 05 November 202 I

A mong educators in the health professions, a growing concern exists around the increasing number of graduate clinical students experiencing mental health issues. ${ }^{1}$ Psychological morbidity, defined as a pathological state involving abnormal levels of negative psychological, emotional, or behavioral states, ${ }^{2}$ is found at a higher rate in medical students than in age-matched peers. $^{3,4}$ Studies within the physical therapy profession show that the occurrence of depression, anxiety, stress, and psychological morbidity among students increases in the final academic year, with evidence suggesting that most stress occurs during the transition from preclinical to clinical training. ${ }^{5-7}$

Because it provides students with an opportunity to apply theoretical knowledge, clinical education is an essential component in physical therapy education. ${ }^{5}$ Doctor of Physical Therapy (DPT) programs include an average of 36 weeks of clinical education within the defined curriculum. Full-time clinical education experiences (CEEs) can take place in different geographic locations, and in many DPT programs, students participate at clinical education sites far away from their academic institutions. ${ }^{8}$ 
Traveling to and living/working in a separate location may isolate students from familiar social and institutional support networks. High academic demand and a low level of support from their institution have been identified as major stressors for DPT students. ${ }^{9}$ Significant variation exists across institutions with regard to: access to counseling and health centers, how those resources are organized and used, and the general policies guiding campus mental health. ${ }^{10}$ Literature has demonstrated that institutional and curricular characteristics have a direct link to student mental health in higher education. ${ }^{11}$

While the length, location, and timing of CEEs vary, the Director of Clinical Education (DCE) at each institution serves as the primary, consistent point of contact for students and their clinical instructors (CIs) during CEEs. The DCE position involves a heavier administrative workload than faculty peers that spans the academic and the clinical environments. ${ }^{12-14}$ Students who face challenges during their CEEs can affect the workload of the DCE significantly. ${ }^{12}$ When student mental health issues arise, the DCE's role as liaison between clinical site and academic program becomes more profound because CIs report feeling significantly less confident managing student mental health issues than addressing concerns about clinical skills for effective patient care. ${ }^{15}$ However, no systematic training - or other preparation - exists for DCEs to prepare them to manage these situations so that they can provide adequate support for both the student and the clinical site.

Role theory serves as the theoretical framework for this study. At its most basic definition, role theory posits that individuals will behave and make decisions based on their prescribed role, the expectations associated with that role, and the situation they are facing. ${ }^{16}$ Research that involves role theory typically requires participants to reflect on their own or others' expectations of the role in question. Associated with role theory is the concept of role conflict and role ambiguity. Role conflict occurs when the demands or expectations of one role interfere with the ability to fulfill the demands of another role. ${ }^{17}$ Role ambiguity refers to a lack of information regarding a role and a resulting unpredictability in an individual's behavior. ${ }^{18}$

The DCE's role itself has undergone examination over the years, at times being questioned on its value and place within the academy. ${ }^{13,14,19}$ Recently, Engelhard et al. $(2018)^{20}$ have offered a conceptual framework of the DCE's role, describing a taxonomy of three responsibilities: processor, coordinator, and director. The efforts to describe and define the DCE's role have been valuable in emphasizing the importance this position serves in physical therapy education. However, there still remains ambiguity in the DCE's role in students' support during CEE, with variability in the level of time, resources, and opportunities DCEs have in supporting students directly when facing challenges in clinical education. ${ }^{12}$
There is currently no existing evidence that examines the role of the DCE when assisting students experiencing mental health challenges during CEEs, nor any current literature that examines the external factors of institutional and curricular characteristics on the DCEs' role in these situations. An examination of the DCE's role during these critical periods provides DPT programs with an opportunity to develop and refine support systems for students struggling with mental health challenges during CEEs, including institutional and curricular factors related to clinical education. This could lead to the implementation of organizational strategies that would simultaneously assist and lessen the burden of DCEs when supporting students during times of mental health crises in CEEs.

The primary purpose of this study was to explore DCE's experiences with, and perceptions of supporting students with mental health challenges during CEEs. For the purposes of this study, the authors defined mental health challenges as those related to anxiety, depression, and/or stress. These three constructs of mental health challenges are the common issues identified in studies out of medicine, exploring the issue of mental health on medical trainees. The authors looked to the medical education literature as a model for defining mental health challenges in physical therapy students because of the lack of clear definition and exploration within the physical therapy field. ${ }^{21-25}$ The aims of this study were framed around the increasing incidence of student mental health concerns within physical therapy, the current knowledge of the DCE's role, and the link between institutional and curricular characteristics to graduate student mental health concerns. Secondary aims included: understanding how frequently DCEs support students with mental health concerns during CEEs and the association that various institutional and curricular factors have on how prepared DCEs feel when doing so.

\section{Methods}

\section{Design}

This descriptive, cross-sectional study utilized a non-experimental, survey methodology designed to collect primarily quantitative data gathered through 43 multiple choice questions as well as qualitative data gathered through four open-ended questions. The survey questions were organized into three sections: demographics of the DCE and clinical education curricular details (questions 1-20), institutional resources related to counseling and psychological support for students (questions 21-28), and the experiences and perceptions of the respondent when supporting student situations involving mental health concerns (questions 29-43). The final survey instrument is presented in Appendix A. The survey was designed to gather DCE's perceptions of expectations placed on them 
in supporting students, and the content of the survey was based on the literature linking specific factors to graduate student mental health. ${ }^{11}$ These factors include, but are not limited to, those related to curricular structure, institutional resources, and faculty preparedness to respond to student crises. In the survey, the term 'mental health concern' was defined as 'those related to depression, anxiety, and/or stress', which is consistent with terminology used in the literature. ${ }^{26}$ At no time were participants asked to speculate on a student's mental health status and were prompted to provide responses based on encounters with student mental health challenges that were reported to the DCE by the student or another individual, not diagnosed or assumed by the DCE. An external individual with content expertise in survey construction consulted with the research team. Prior to distribution, the survey was assessed by another external reviewer for content, readability, and length. The survey and the study were approved by the Institutional Review Board at the researchers' institution.

\section{Subjects}

The investigators invited 220 current DCEs from accredited DPT programs in the United States and its territories to participate in an electronic survey. The Commission on Accreditation in Physical Therapy (CAPTE) website and the public facing websites associated with each academic program served as sources of contact information. To avoid duplication, only one representative from each institution received an invitation, even if multiple DCEs or an assistant DCE was listed. Preference was given to those with the DCE title. If no distinction was apparent, the representative was chosen based on order of appearance on academic program website.

\section{Procedure}

The survey was distributed via email and accessed through an anonymous, online link using the Qualtrics (Provo, UT) platform. Potential participants were informed that submission of the online survey served as consent to participate in the study. Two email reminders were sent over the course of 30 days. Survey data were downloaded from Qualtrics into IBM SPSS Statistics, version 25.0 (Armonk, NY) for analysis.

\section{Coding of survey variables}

Within the survey items that were selected as characteristics to include in data analysis, all choices were binary (e.g. yes or no) with the exception of six questions. For the questions that had more than two choices, we either dummy-coded the variables to compare against the other selections, or we collapsed two choices into a single answer, using a logical selection method. For question 12 (length of TCEs), we collapsed into ' $10-14$ weeks' and ' 15 weeks or greater'. For questions 15 and
16 (percentage of students completing $\geq 1$ TCE within 1 hour of campus and percentage of students completing >1 TCE out of state), we combined ' $50-99 \%$ ' and ' $100 \%$ ' into one answer. Question 5 was dummy-coded to allow representation of both 'majority of students were non-traditional' and 'mixed cohort of traditional and non-traditional students'. Each of these variables was represented uniquely in the analyses.

On two occasions, we elected to both collapse code a variable and dummy code the variable for two different analyses. For question 1 (DCE experience), we collapsed $<1$ year and 1-10 years into one variable to evaluate this against known student mental health challenges. We also dummy-coded the variable into three choices while evaluating preparedness. For question 18 (method for matching students to TCEs), we collapsed 'without student input' and 'other' into a group since there were multiple reports of 'other' forms of selection that most closely represented options that did not involve student input. We also dummy-coded the variable to explore the three unique choices when evaluating preparedness.

\section{Analysis}

Respondent characteristics were tabulated using mean and standard deviation and/or proportions. The proportion of DCEs who reported being made aware of student(s) with mental health concerns during CEEs was identified using simple frequencies. For the purposes of this study, mental health challenges were considered present if the DCE was made aware of an issue through student disclosure and/or conversations with the students' CI. Students did not necessarily have a clinical diagnosis of anxiety, depression, or stress disorder.

The analysis included three series of models. Two series included the same dependent variable, DCE awareness of student mental health challenges. One series included the dependent variable, DCE preparedness for addressing student mental health challenges. Each model within each series included one different independent variable, which represented a question in the survey.

In series 1 , we explored the relationship of clinical education curriculum characteristics and DCEs' awareness of students' mental health issues. In series 2, we explored the relationship of academic institution characteristics and DCEs' awareness of students' mental health issues. The DCE's awareness of student mental health challenges was indicated through yes/no response to question 29 (see Appendix A.) The selected characteristics for both series are detailed in Table 3, and the referent categories used to distinguish the relationships are indicated within the table.

In series 3, we explored the relationship of selected clinical education curriculum characteristics and academic institution characteristics to a DCE's feeling of 
preparedness to assist students with mental health challenges. DCEs indicated their feeling of preparedness through a yes/no response to question 41 in the survey (see Appendix A.) The selected characteristics for series 3 are detailed in Table 4 and the referent categories used to distinguish the relationships are indicated within the table.

\section{Relationship among variables}

For all series, we used individual bivariate binary logistic regression analyses to explore a single variable from the survey to the outcome measure of DCE's awareness of mental health concerns or an increase in mental health prevalence. For each analysis, we reported the odds ratios (ORs) and 95\% confidence intervals (CI), the $P$-value, and the Nagelkerke $R^{2}$. Each predictor had a designated Nagelkerke $R^{2}$. A Nagelkerke is an upward bound correction of the Cox and Snell (in an effort to assume, it is similar to a linear $R^{2}$ ) that adjusts the scale of the statistic to cover the full range from 0 to 1 , with values closer to 1 reflecting a stronger explanatory relationship between the independent variable and the outcome variable. Missing data were excluded from analysis.

Item analysis of open-ended questions

The survey included four open-ended questions related to the DCE's perception of barriers, supports, and needs when supporting student mental health concerns during CEEs. The researchers employed an inductive coding process to analyze the narrative responses of each question separately. ${ }^{27}$ An open coding approach was utilized initially, with the researchers assigning codes to each survey response. For integrity purposes, the researchers coded the same 10 responses independently. The codes were then examined, and differences were discussed until agreement was reached. Through this process, the researchers developed a set of codes that was then used to continue the open coding process. Following this initial review, the codes were grouped into categories using thematic analysis coding. The researchers collaboratively determined major categories represented by the codes, as well as subcategories for each.

\section{Results}

\section{Participant characteristics}

The response rate was $48 \%$, with 106 responses received. Participant demographic characteristics, including demographics of clinical education curriculum and academic institutional resources, are included in Table 1. Most (52.8\%) participants had between 1 and 10 years of experience and represented programs housed within a private institution with cohort sizes of less than 50 students.

\section{Prevalence of DCE experience with student mental health concerns}

Most participants $(73.6 \%)$ indicated that they had been made aware of a student(s) experiencing a mental health concern during a full-time CEE in the past 3 years. In 77\% of these cases, the DCEs indicated that students reached out to them directly when struggling with mental health concerns. The remaining 33\% of DCEs were made aware of a student challenge via the $\mathrm{CI}$ or the site coordinator of clinical education (SCCE) contacting the DCE to discuss concerns.

Table 2 includes descriptors of the experiences of DCEs who were aware of students struggling with mental health concerns. These DCEs indicated student mental health concerns reported to them ranged across all three areas of depression, anxiety, and stress, with the most situations involving anxiety. When made aware of a student with a mental health concern, most of those respondents $(82.1 \%)$ performed a site visit and approximately half of the respondents $(51.3 \%)$ indicated that they terminated a CEE early.

\section{Relationship to clinical education curricular characteristics}

The first section of Table 3 outlines the ORs of all the investigated predictors related to the clinical education curriculum. Two variables were linked to a DCE being made aware of a student with a mental health concern. Analysis found that a DCE has greater odds of being made aware of a student mental health challenge with terminal clinical experiences (TCEs) longer than 10 weeks $(\mathrm{OR}=2.86$; $95 \%$ CI $=1.19,6.84)$. The odds of a DCE being made aware of a student challenge also increase if the clinical education curriculum requirement includes students completing at least one of their CEs out of state $(\mathrm{OR}=3.09$; $95 \% \mathrm{CI}=1.18,8.11)$.

\section{Relationship to academic institution characteristics}

The second section of Table 3 outlines the ORs of all the investigated predictors related to characteristics of the academic program and institution. In this analysis, two variables were again linked to greater odds of a DCE being made aware of a student with a mental health concern. First, cohort size of greater than 50 students increased the odds $(\mathrm{OR}=5.00 ; 95 \% \mathrm{CI}=1.56,16.04)$. Additionally, the unavailability of online or video counseling services also increased the odds a DCE was aware of this type of student challenge $(\mathrm{OR}=8.10 ; 95 \% \mathrm{CI}=1.03,63.95)$.

\section{Relationship to DCEs' feeling prepared}

Forty-six percent of DCEs indicated that they felt prepared to deal with mental health issues, while 35\% were 'unsure'. There were no curricular or institutional variables that were statistically related to a DCE's feeling of preparedness (Table 4). 
Table 1. Demographics of respondents and curricular and academic institution characteristics

\begin{tabular}{|c|c|}
\hline Demographic & Number (\%) \\
\hline \multicolumn{2}{|l|}{ Years as a DCE/ADCE } \\
\hline$<$ l year & $5(4.7 \%)$ \\
\hline $1-10$ years & $56(52.8 \%)$ \\
\hline$>10$ years & 45 (42.4\%) \\
\hline \multicolumn{2}{|l|}{ Type of academic institution } \\
\hline Private & $55(5 \mathrm{I} .8 \%)$ \\
\hline Public & 51 (48.1\%) \\
\hline \multicolumn{2}{|l|}{ Average cohort size } \\
\hline$<50$ students & $6 \mathrm{I}(57.5 \%)$ \\
\hline$>50$ students & 45 (42.4\%) \\
\hline \multicolumn{2}{|l|}{ Cohort demographic } \\
\hline $\begin{array}{l}\text { Majority non-traditional (i.e. students entering } \\
\text { program after time laps between undergraduate } \\
\text { degree completion and/or second career) }\end{array}$ & I (0.9\%) \\
\hline $\begin{array}{l}\text { Majority traditional (i.e. entering directly from } \\
\text { undergraduate) }\end{array}$ & $71(66.9 \%)$ \\
\hline Mixed cohort & $34(32.0 \%)$ \\
\hline \multicolumn{2}{|l|}{$\begin{array}{l}\text { Total number of full-time, non-Integrated Clinical } \\
\text { Education (ICE) experiences in curriculum }\end{array}$} \\
\hline 2-3 clinical experiences & 37 (34.9\%) \\
\hline 4-6 clinical experiences & $69(65.1 \%)$ \\
\hline \multicolumn{2}{|l|}{$\begin{array}{l}\text { Presence of full-time, non-ICE clinical } \\
\text { experiences before completion of didactic curriculum }\end{array}$} \\
\hline Yes & $89(84.0 \%)$ \\
\hline No & $17(16.0 \%)$ \\
\hline \multicolumn{2}{|l|}{$\begin{array}{l}\text { Number of Terminal Clinical Experiences (TCEs) } \\
\text { in curriculum }\end{array}$} \\
\hline I-2TCEs & 74 (71.1\%) \\
\hline $3-4$ TCEs & $30(28.8 \%)$ \\
\hline \multicolumn{2}{|l|}{ Length of TCEs } \\
\hline 7-9 weeks & 20 (19.4\%) \\
\hline 10-14 weeks & $68(66.0 \%)$ \\
\hline $15+$ weeks & $15(14.6 \%)$ \\
\hline \multicolumn{2}{|l|}{ Student requirement to go out of state for TCE } \\
\hline Yes & 14 (13.5\%) \\
\hline No & $90(86.5 \%)$ \\
\hline \multicolumn{2}{|l|}{$\begin{array}{l}\text { Average percentage of students who complete } \geq 1 \\
\text { TCE within I hour of campus }\end{array}$} \\
\hline $0-49 \%$ of students & $28(27.2 \%)$ \\
\hline $50-99 \%$ of students & $57(55.3 \%)$ \\
\hline $100 \%$ of students & 18 (I7.4\%) \\
\hline \multicolumn{2}{|l|}{$\begin{array}{l}\text { Average percentage of students who complete } \geq 1 \\
\text { TCE out of state }\end{array}$} \\
\hline $0-49 \%$ of students & $50(48.5 \%)$ \\
\hline $50-99 \%$ of students & $50(48.5 \%)$ \\
\hline $100 \%$ of students & $3(2.9 \%)$ \\
\hline \multicolumn{2}{|l|}{$\begin{array}{l}\text { Average percentage of student who complete all TCEs } \\
\text { out of state }\end{array}$} \\
\hline$<25 \%$ of students & 74 (79.6\%) \\
\hline$>25 \%$ of students & 19 (20.4\%) \\
\hline
\end{tabular}

Table 1. (Continued)

\begin{tabular}{ll}
\hline Demographic & Number (\%) \\
\hline Method for matching students to TCEs & \\
With student input & $92(90.2 \%)$ \\
Without student input & $4(3.9 \%)$ \\
Other unknown & $6(5.9 \%)$ \\
Policy restricting location of TCE if medical or mental & \\
health diagnosis disclosed & \\
Yes & $100(97.1 \%)$ \\
No & $3(2.9 \%)$ \\
Available counseling and support services at institution & \\
One-on-one counseling & $103(100 \%)$ \\
Group counseling sessions & $33(32.0 \%)$ \\
Online/Skype or other video counseling services & $22(21.4 \%)$ \\
Online educational material & $53(51.5 \%)$ \\
Group classes & $46(44.7 \%)$ \\
Faculty receives training on student referral to & \\
support services & \\
Yes & $74(71.8 \%)$ \\
No & $29(28.1 \%)$ \\
Student access to institution's counseling/support & \\
services when away from campus during TCEs & \\
Yes & $69(67.0 \%)$ \\
No & $33(32.0 \%)$ \\
\hline
\end{tabular}

Challenges in supporting students with mental health concerns Figure 1 depicts the major categories and associated subcategories identified as challenges in providing support to students. DCEs commented frequently on student characteristics as being a significant challenge, with student reluctance to disclose their concerns to the DCE and their willingness to accept and utilize assistance as specific challenges. The category of 'DCE Role' included responses that were related to the complex role of a DCE, including the time needed to support student issues, as well as the role of liaison between academic and clinical stakeholders. The 'Clinical Environment' category included any responses that were related to clinical characteristics including the clinic culture and attributes of the CI.

\section{Factors influencing DCE-perceived preparedness}

All participants responded to the question, 'As the DCE, do you feel prepared to assist students with mental health concerns during their CEEs?' and were asked to provide either reasons for preparedness or indicate what would help them feel more prepared. Figure 1 also includes the major categories and subcategories for both responses. Most respondents who indicated feeling prepared identified available institutional resources and overall experience as the two areas that led to their sense of preparedness. Institutional resources included trainings provided to faculty, awareness of available resources, and a feeling that counseling resources were easily accessible when referred. 
Table 2. Descriptors of DCE's experiences supporting students with mental health concerns during CEEs

\begin{tabular}{lc}
\hline Descriptor & Number (\%) \\
\hline \# of students reported in previous 3 years & $6(7.6 \%)$ \\
I student & $56(71.8 \%)$ \\
$2-5$ students & $16(20.5 \%)$ \\
$>5$ students & \\
Types of mental health concerns reported & $49(62.8 \%)$ \\
Depression & $75(96.1 \%)$ \\
Anxiety & $67(85.9 \%)$ \\
Stress & \\
Actions taken to support students & $67(85.9 \%)$ \\
Refer student to academic institution's counseling & \\
and support services & $76(97.4 \%)$ \\
Spoke with student on the phone & $64(82.1 \%)$ \\
Performed a site visit & $61(78.2 \%)$ \\
Involved the Cl and/or SCCE (with student permission) & $40(51.3 \%)$ \\
\hline Terminated the clinical experience early & \\
\hline
\end{tabular}

The category of 'Experience' included responses that described work experience and personal experience.

DCEs who did not feel prepared also indicated that more training/education would be helpful. The subcategories included focused training on screening for mental health concerns and guidelines that exist for referring and supporting students in these situations. Respondents also indicated that understanding the scope of their professional role with regard to legal guidelines would provide preparation. Finally, DCEs commented frequently on the need for more institutional support, indicating that support of their time and workload to manage student needs would prepare them for these unique situations.

\section{Discussion}

The present study is the first of its kind to investigate the perceptions and experiences of DCEs managing students with mental health concerns during CEEs. Recently, the physical therapy profession has taken steps to understand and address the topic of mental health among students. In 2019, the American Council of Academic Physical Therapy developed the 'Task Force on Enhancing Programs Awareness to Student Clinician Mental Health and Wellness'. One of the task force's objectives is to understand what factors influence student mental health during their professional education. ${ }^{28}$ This study reveals that a majority of DCEs have been in a position to support a student facing a mental health concern during CEEs, but expose a gap in the DCE's preparedness and institutional support for their role in these types of situations. The data also reveal relationships between certain curricular and institutional characteristics to the prevalence of DCEs supporting students who are facing mental health challenges. These relationships further contribute to the exploration of causes behind the increasing incidence of students experiencing psychological morbidity in healthcare professional programs.

\section{Prevalence}

The majority of DCEs in our study had supported at least one student recently who was struggling with mental health concerns. The participants indicated that anxiety was the most common issue students disclosed. This is in line with national trends in graduate student education, with depression and anxiety occurring at a much larger rate than that of the general population. ${ }^{1}$ Additionally, healthcare professional students have higher rates of anxiety than the general population. ${ }^{29}$ In our study, most DCEs indicated being made aware of -one to five students in the past 3 years who were struggling with depression, anxiety, and/or stress during CEEs. While this number may seem low when considering the number of students enrolled in DPT programs, one factor that DCEs brought up as a barrier to assisting students was student willingness to disclose mental health concerns. A student's relationship with faculty is an important element in considering whether they reach out for support $\mathrm{t}^{23}$ and indicate that a level of trust between student and DCE is an important factor when considering how best to support students in these situations.

\section{Impact on the DCE position}

The DCE's role is complex and dynamic, with roles and responsibilities that differentiate it from more traditional faculty appointments in DPT programs. ${ }^{13}$ DCEs serve an important role in supporting students both before and during CEEs, a role that is difficult to quantify but remains a core aspect of the DCE position. ${ }^{13,14}$ The high administrative expectation of the DCE role has resulted in high variability among DCE workload distribution and teaching expectations across academic institutions. ${ }^{12}$ When a student is struggling with mental health concerns during CEEs, the DCE's support of the student presents a new challenge, as the time required to support the student potentially, and most likely, increases.

DCEs also serve as support to clinical faculty during CEEs. A recent study indicated that clinicians are not confident in managing any student mental health issue arising during CEEs. ${ }^{15}$ Therefore, the DCE role in these situations may extend beyond supporting the student, but also supporting the CI. In our study, the DCEs described taking many different steps when made aware of a student struggling with mental health issues, including talking with the student directly, engaging with the CI and the SCCE, and/ or performing a site visit. These actions typically require increased overall time, as well as institutional resources such as financial support for travel and protected work effort. 
Table 3. Which clinical education and curriculum factors are related to mental health concerns?

\begin{tabular}{|c|c|c|c|}
\hline Variable & $\begin{array}{l}\text { Odds ratio and } 95 \% \\
\text { confidence interval }\end{array}$ & $P$ & Nagelkerke $R^{2}$ \\
\hline \multicolumn{4}{|l|}{ Relationship to clinical education curricular factors } \\
\hline $\begin{array}{l}\text { Question 7: Number of full-time, non-ICE clinical experiences (referent } \\
\text { category = 4-6) }\end{array}$ & $0.74(0.27,1.72)$ & 0.55 & 0.01 \\
\hline $\begin{array}{l}\text { Question 8: Full-time, non-ICE clinical experiences before completion of } \\
\text { didactic coursework (referent category = yes) }\end{array}$ & $1.16(0.36,4.01)$ & 0.82 & 0.01 \\
\hline Question I I: Number of TCEs (referent category = 3-4) & $0.96(0.35,2.63)$ & 0.93 & 0.00 \\
\hline Question I2: Length of TCEs (referent category = 7-9 weeks) & $2.86(1.19,6.84)$ & 0.02 & 0.09 \\
\hline $\begin{array}{l}\text { Question I3: Out of state requirement for full-time clinical experiences } \\
\text { (referent category }=\text { yes) }\end{array}$ & $4.00(.49,32.54)$ & 0.18 & 0.04 \\
\hline $\begin{array}{l}\text { Question I5: Percentage of students completing } \geq \text { I full-time clinical } \\
\text { experience within I hour of campus (referent category }=50-100 \% \text { ) }\end{array}$ & $1.02(0.50,2.08)$ & 0.95 & 0.00 \\
\hline $\begin{array}{l}\text { Question I6: Percentage of students completing } \geq \text { I full-time clinical } \\
\text { experience out of state (referent category }=<50 \% \text { ) }\end{array}$ & $3.09(1.18,8.11)$ & 0.02 & 0.09 \\
\hline $\begin{array}{l}\text { Question 17: Percentage of students completing all full-time clinical } \\
\text { experiences out of state (referent category }=\mathbf{> 2 5} \% \text { ) }\end{array}$ & $1.64(0.43,6.34)$ & 0.47 & 0.01 \\
\hline $\begin{array}{l}\text { Question I8: Method for matching students to TCEs (referent category } \\
=\text { other) }\end{array}$ & $0.87(0.17,4.45)$ & 0.87 & 0.00 \\
\hline $\begin{array}{l}\text { Question 19: Policy restricting location of TCE if medical or mental health } \\
\text { diagnosis disclosed (referent category = yes) }\end{array}$ & $0.58(0.05,6.68)$ & 0.67 & 0.00 \\
\hline \multicolumn{4}{|l|}{ Relationship to academic institution characteristics } \\
\hline $\begin{array}{l}\text { Question I: Years of experience as DCE/ACCE (referent category }=>10 \\
\text { years) }\end{array}$ & $1.56(0.69,3.48)$ & 0.27 & 0.02 \\
\hline Question 2: Type of institution (referent category = public) & $0.52(0.20,1.35)$ & 0.18 & 0.03 \\
\hline Question 4: Average cohort size (referent category $=<50$ ) & $5.00(1.56,16.04)$ & $<0.01$ & 0.13 \\
\hline $\begin{array}{l}\text { Question 5: Majority of students 'non-traditional' (referent category = all } \\
\text { other choices) }\end{array}$ & $0.47(0.16,1.76)$ & 0.18 & 0.03 \\
\hline $\begin{array}{l}\text { Question 5: Mixed cohort of 'traditional' and 'non-traditional' students } \\
\text { (referent category = all other choices) }\end{array}$ & $2.81(0.87,9.01)$ & 0.08 & 0.05 \\
\hline $\begin{array}{l}\text { Question } 2 \text { I b: Group Counseling Sessions offered by institution } \\
\text { (referent category = no) }\end{array}$ & $1.08(0.38,1.19)$ & 0.88 & 0.00 \\
\hline $\begin{array}{l}\text { Question } 2 \text { I c: Online counseling services offered by institution } \\
\text { (referent category = no) }\end{array}$ & $8.10(1.03,63.95)$ & 0.04 & 0.10 \\
\hline $\begin{array}{l}\text { Question } 2 \text { Id: Online educational material offered by institution } \\
\text { (referent category = no) }\end{array}$ & $1.59(0.63,4.08)$ & 0.33 & 0.01 \\
\hline $\begin{array}{l}\text { Question } 2 \text { l e: Group support classes offered by institution } \\
\text { (referent category = no) }\end{array}$ & $2.9(0.84,6.16)$ & 0.10 & 0.04 \\
\hline $\begin{array}{l}\text { Question 22: Faculty training on student referral to support services } \\
\text { (referent category = no) }\end{array}$ & $1.86(0.70,4.96)$ & 0.21 & 0.02 \\
\hline $\begin{array}{l}\text { Question 27: Access to institution's counseling/support services when away } \\
\text { from campus during CEEs (referent category }=\text { no) }\end{array}$ & $2.33(0.89,6.06)$ & 0.08 & 0.04 \\
\hline $\begin{array}{l}\text { Question 4I: DCE's preparedness to assist students with mental health } \\
\text { concerns during CEEs (referent category }=\text { no) }\end{array}$ & $0.91(0.36,2.31)$ & 0.84 & 0.01 \\
\hline
\end{tabular}

$p=<0.05$.

The participants in this study, however, recognized that one of the biggest challenges they have in supporting students in these situations is time. McCallum et al. ${ }^{12}$ describe that various external factors, such as accreditation requirements, financial resources, and workload determinations, can affect a DCE's ability to function effectively and efficiently during times of students' struggle. Further investigation into the complexities of time constraints and workload expectations of those in the DCE position may assist in further understanding the specific needs of DCEs when they face the need to support a student in mental health crisis.

Academic institution and curricular characteristics To our knowledge, this study is the first to link academic institution and curricular characteristics to the number 
Table 4. Which institutional and curricular factors are related to DCEs feeling prepared to assist students with mental health challenges?

\begin{tabular}{|c|c|c|c|}
\hline Variable & $\begin{array}{l}\text { Odds ratio and } 95 \% \\
\text { confidence interval }\end{array}$ & $P$ & Nagelkerke $R^{2}$ \\
\hline $\begin{array}{l}\text { Question I: Years of experience as DCE/ACCE (referent category }=<1 \\
\text { year) }\end{array}$ & $0.77(0.12,4.83)$ & 0.78 & 0.001 \\
\hline $\begin{array}{l}\text { Question I: Years of experience as DCE/ACCE (referent category = } \\
\text { I-10 years) }\end{array}$ & I.0I $(0.46,2.22)$ & 0.97 & 0.000 \\
\hline $\begin{array}{l}\text { Question I: Years of experience as DCE/ACCE (referent category = } \\
>10 \text { years) }\end{array}$ & $\mathrm{I} .03(0.46,2.29)$ & 0.92 & 0.000 \\
\hline $\begin{array}{l}\text { Question 2: Type of institution (Public, private, rural, urban/suburban) } \\
\text { (referent category = public) }\end{array}$ & $1.16(0.52,2.55)$ & 0.71 & 0.002 \\
\hline Question 4: Average cohort size (referent category $=<50$ ) & $0.69(0.31,1.53)$ & 0.36 & 0.011 \\
\hline $\begin{array}{l}\text { Question 5: Majority of students 'traditional' (referent category = all } \\
\text { other choices) }\end{array}$ & I. $12(0.48,2.57)$ & 0.78 & 0.001 \\
\hline $\begin{array}{l}\text { Question 5: Mixed cohort of 'traditional' and 'non-traditional' students } \\
\text { (referent category = all other choices) }\end{array}$ & $0.96(0.41,2.23)$ & 0.93 & 0.000 \\
\hline Question 13: Out of state requirement for TCE (referent category = yes) & $0.54(0.15,1.95)$ & 0.35 & 0.012 \\
\hline $\begin{array}{l}\text { Question 18: Method for matching students to TCEs (referent category = } \\
\text { Student input provided) }\end{array}$ & $0.85(0.23,3.15)$ & 0.81 & 0.001 \\
\hline $\begin{array}{l}\text { Question 18: Method for matching students to TCEs (referent category = } \\
\text { Student input not provided) }\end{array}$ & I.I5 $(0.15,8.57)$ & 0.88 & 0.000 \\
\hline $\begin{array}{l}\text { Question I8: Method for matching students to TCEs (referent category = } \\
\text { variable whether student input is provided) }\end{array}$ & $1.16(0.22,6.06)$ & 0.85 & 0.000 \\
\hline $\begin{array}{l}\text { Question } 2 \text { I b: Group counseling sessions offered by institution } \\
\text { (referent category }=\text { no) }\end{array}$ & $\mathrm{I} .05(0.45,2.44)$ & 0.90 & 0.000 \\
\hline $\begin{array}{l}\text { Question } 2 \text { I c: Online counseling services offered by institution } \\
\text { (referent category = no) }\end{array}$ & I.55 $(0.60,4.02)$ & 0.36 & 0.011 \\
\hline $\begin{array}{l}\text { Question } 2 \text { Id: Online educational material offered by institution } \\
\text { (referent category }=\text { no) }\end{array}$ & $\mathrm{I} .80(0.8 \mathrm{I}, 4.0 \mathrm{I})$ & 0.15 & 0.03 \\
\hline $\begin{array}{l}\text { Question } 2 \text { l e: Group support classes offered by institution } \\
\text { (referent category = no) }\end{array}$ & I.58 $(0.7 \mathrm{I}, 3.50)$ & 0.25 & 0.017 \\
\hline $\begin{array}{l}\text { Question 22: Faculty training on student referral to support services } \\
\text { (referent category = no) }\end{array}$ & $\mathrm{I} .30(0.54,3 . \mathrm{II})$ & 0.55 & 0.005 \\
\hline $\begin{array}{l}\text { Question 29: DCE aware of student experiencing mental health concern } \\
\text { during full-time clinical experience in last } 3 \text { years (referent category }=\text { no) }\end{array}$ & I.37 $(0.58,3.22)$ & 0.46 & 0.007 \\
\hline
\end{tabular}

of students experiencing mental health challenges during CEEs. It is not surprising that if the cohort is larger and/ or the $\mathrm{CE}$ experiences are longer, there is greater opportunity for the DCE to encounter students' mental health challenges. Despite the obvious nature of these links, it does not minimize their importance and implications for future considerations of academic programs. Currently, the average class size for DPT programs is 45 students and while this number has stayed consistent for the past 2 years, there has been an overall steady increase in planned class size in the past decades. ${ }^{30}$ If class sizes continue to increase, and the number of healthcare professional students experiencing mental health challenges continues to rise, academic programs may need to address the DCE's time and workload in preparation for supporting students effectively.

Similarly, the structure and sequence of the clinical education curriculum may be a factor in the prevalence of students experiencing mental health challenges during
CEEs. Clinical education curricular characteristics are influenced by many factors, including the increasing number of DPT programs ${ }^{30}$ that can impact the availability of clinical placements. To maximize clinical opportunities and meet the needs of their students, academic programs are partnering with an increased number of clinical sites nationwide, ${ }^{31}$ which can result in students relocating to areas where institutional counseling support may not be available.

Full institutional student counseling and support resources may not extend to out-of-state locations, but may be available through online or video conferencing methods. ${ }^{32}$ Whether an institution's counseling and psychological support services offer online or video counseling depends on the laws of the psychology board for the state in which the institution is located. ${ }^{32}$ Because there is no national standardization for practicing telehealth for counseling and psychological services, resources vary greatly among institutions, and therefore, between states. ${ }^{32}$ 


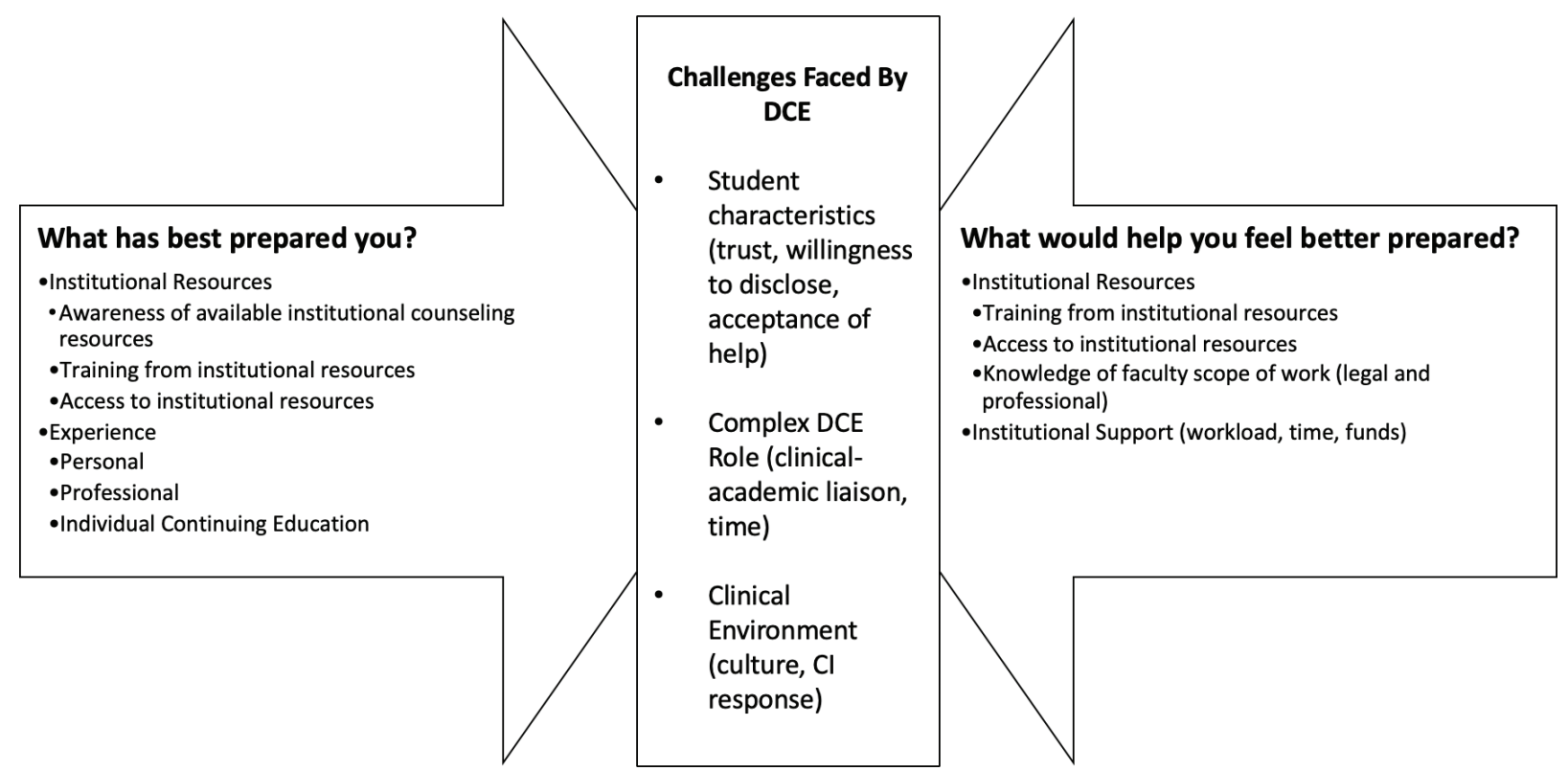

Fig. 1. Factors contributing to DCE feeling of preparedness to support students during mental health challenges.

In our study, DCEs did refer students to institutional counseling and support services as one response measure when notified of a struggling student. It is important that DCEs understand the availability of resources at their institution, as well as the geographic limits to those services.

\section{Preparing and supporting the DCE}

Less than half of DCEs surveyed in this study feel prepared to assist students with mental health concerns during CEEs. Recent research has shown that the majority of DCEs do not have previous academic experience when entering this faculty role, with training occurring 'on the job'. ${ }^{12}$ In our study, there were no specific curricular or institutional variables that predicted a DCE's feeling of preparedness. However, those DCEs who did indicate feeling prepared pointed to mentorship and trainings provided by institutions as positive influencers on their perception of preparedness. Academic institutions may consider including trainings specifically focused on student mental health responsiveness as well as identifying faculty mentors as part of the onboarding process for new DCEs. This could potentially influence the DCE's ability to successfully and effectively respond to a student struggling during CEEs.

\section{Limitations}

Our data reflect the perceptions and experiences exclusively of current DCEs for accredited DPT programs in the United States and its territories. Therefore, the generalizability of our findings is limited and may not reflect the perceptions and experiences of other academic faculty, clinical faculty, or students. Additionally, our results are not specific to the physical therapist assistant (PTA) population. However, we speculate that with the aforementioned mental health concerns associated with clinical education, data from the PTA student population may reflect similar results if examined. Another limitation of this study is that our data reflect the perceptions and experiences of DCEs managing student mental health challenges specifically during CEEs. We therefore are unable to determine if these issues are isolated to the clinical environment or are also present during the didactic aspect of curriculums. Also, because survey respondents had to be made aware of students facing mental health challenges during CEEs in the previous 3 years, our findings may not be indicative of the current environment due to a potential lack of student disclosure of issues to their respective DCEs. Further exploration is needed to examine the student perspective, the needs of CIs, and various other roles to understand the perspectives and experiences of all stakeholders involved.

\section{Conclusion}

This is the first study to evaluate the experiences and perceptions of the DCE while supporting students with mental health challenges during CEEs. This study highlights a significant challenge that DCEs face when supporting students during CEEs and contributes a new perspective on the impact of academic and institutional factors on student mental health. The ability of a DCE to effectively support students during times of mental health crises may be positively impacted by an examination of the DCE workload and institutional and curricular factors identified in this study. Better supported DCEs and 
subsequently, better supported students, can lead to positive effects on student performance, readiness to practice, patient care, and clinical partnerships.

\section{Conflict of interest and funding}

The authors have no conflicts of interest and funding.

\section{Disclosures}

Manuscript content was previously presented at an education session at the Educational Leadership Conference in Bellevue, WA, on Friday, October 18, 2019.

\section{Ethical approval}

Duke University Health System Institutional Review Board, Protocol ID: Pro00101475.

\section{References}

1. Evans TM, Bira L, Gastelum JB, et al. Evidence for a mental health crisis in graduate education. Nat Biotechnol (2018) 36(3): 282-84. doi: 10.1038/nbt.4089

2. Craig A, Tran Y, Middleton J. Psychological morbidity and spinal cord injury: a systematic review. Spinal Cord (2009) 47(2): 108-14. doi: 10.1038/sc.2008.115

3. Schwenk TL, Davis L, Wimsatt LA. Depression, stigma, and suicidal ideation in medical students. JAMA (2010) 304(11): 1181-90. doi: 10.1001/jama.2010.1300

4. Baker K, Sen S. Healing medicine's future: prioritizing physician trainee mental health. AMA J Ethics (2016) 18(6): 604-13. doi: 10.1001/journalofethics.2016.18.6.medu1-1606

5. Alshahrani Y, Cusack L, Rasmussen P. Undergraduate nursing students' strategies for coping with their first clinical placement: descriptive survey study. Nurse Educ Today (2018) 69: 104-8. doi: 10.1016/j.nedt.2018.07.005

6. Syed A, Ali SS, Khan M. Frequency of depression, anxiety and stress among the undergraduate physiotherapy students. Pak J Med Sci (2018) 34(2): 468-71. doi: 10.12669/pjms.342.12298

7. Walsh JM, Feeney C, Hussey J, et al. Sources of stress and psychological morbidity among undergraduate physiotherapy students. Physiotherapy (2010) 96(3): 206-12. doi: 10.1016/j. physio.2010.01.005

8. Jette DU, Nelson L, Palaima M, et al. How do we improve quality in clinical education? examination of structures, processes, and outcomes. J Phys Ther Educ (2014) 28. Available from: https://journals.lww.com/jopte/Fulltext/2014/00001/How_Do_ We_Improve_Quality_in_Clinical_Education_.4.aspx [cited 06 March 2020].

9. Biro E, Veres-Balajti I, Kosa K. Social support contributes to resilience among physiotherapy students: a cross sectional survey and focus group study. Physiotherapy (2016) 102(2): 189-95. doi: 10.1016/j.physio.2015.05.002

10. Hunt J, Eisenberg D. Mental health problems and help-seeking behavior among college students. J Adolesc Health (2010) 46(1): 3-10. doi: 10.1016/j.jadohealth.2009.08.008

11. Hyun JK, Quinn BC, Madon T, et al. Graduate Student Mental Health: Needs Assessment and Utilization of Counseling Service J Coll Stud Dev (2006) 47(3): 247-66. doi: 10.1353/csd.2006.0030

12. Mccallum C, Engelhard C, Applebaum D, et al. Contemporary role and responsibilities of the director of clinical education: a national qualitative study. J Phys Ther Educ (2018) 32: 1. doi: 10.1097/JTE.0000000000000049

13. Salzman A. Portraits of persistence: professional development of successful directors of clinical education. J Phys Ther Educ (2009) 23(1). Available from: https://journals.lww.com/jopte/ Fulltext/2009/01000/Portraits_of_Persistence_Professional_ Development.7.aspx [cited 27 January 2020].

14. Strickler EM. The academic coordinator of clinical education: current status, questions, and challenges for the 1990s and beyond. J Phys Ther Educ (1991) 5(1). Available from: https://journals. lww.com/jopte/Fulltext/1991/01000/The_Academic_Coordinator_of_Clinical_Education_.2.aspx [cited 27 January 2020].

15. Lo K, Curtis H, Keating JL, et al. Physiotherapy clinical educators' perceptions of student fitness to practise. BMC Med Educ (2017) 17(1): 16-016-0847-2. doi: 10.1186/s12909016-0847-2

16. Biddle BJ. Recent developments in role theory. Annu Rev Sociol (1986) 12(1): 67-92. doi: 10.1146/annurev.so.12.080186. 000435

17. Hecht LM. Role conflict and role overload: different concepts, different consequences. Sociol Inquiry (2001) 71(1): 111-21. doi: 10.1111/j.1475-682X.2001.tb00930.x

18. Pearce JL. Bringing some clarity to role ambiguity research. AMR (1981) 6(4): 665-74. doi: 10.5465/amr.1981.4285727

19. Buccieri KM, Brown R, Malta S. Evaluating the performance of the academic coordinator/director of clinical education: tools to solicit input from program directors, academic faculty, and students. J Phys Ther Educ (2011) 25(2). Available from: https:// journals.lww.com/jopte/Fulltext/2011/01000/Evaluating_the_ Performance_of_the_Academic.6.aspx [cited 29 March 2020].

20. Engelhard C, McCallum C, Applebaum D, et al. Development of an innovative taxonomy and matrix through examination of the director of clinical education's roles and responsibilities. J Phys Ther Educ (2018) 32(4). Available from: https://journals. lww.com/jopte/Fulltext/2018/12000/Development_of_an_Innovative_Taxonomy_and_Matrix.3.aspx [cited 06 January 2020].

21. Ahmed I, Banu H, Al-Fageer R, et al. Cognitive emotions: depression and anxiety in medical students and staff. J Crit Care (2009) 24(3): e1-7. doi: 10.1016/j.jcrc.2009.06.003

22. Dahlin ME, Runeson B. Burnout and psychiatric morbidity among medical students entering clinical training: a three year prospective questionnaire and interview-based study. BMC Med Educ (2007) 7(1): 6. doi: 10.1186/1472-6920-7-6

23. Dyrbye LN, Thomas MR, Shanafelt TD. Medical student distress: causes, consequences, and proposed solutions. Mayo Clin Proc (2005) 80(12): 1613-22. doi: 10.4065/80.12.1613

24. Grant A, Rix A, Winter P, et al. Support for medical students with mental health problems: a conceptual model. Acad Psychiatry (2015) 39(1): 16-21. doi: 10.1007/s40596-014-0154-3

25. Sreeramareddy CT, Shankar PR, Binu VS, et al. Psychological morbidity, sources of stress and coping strategies among undergraduate medical students of Nepal. BMC Med Educ (2007) 7(1): 26. doi: 10.1186/1472-6920-7-26

26. American Psychiatric Association. Diagnostic and statistical manual of mental disorders. 5th ed. Washington, DC: American Psychiatric Association; 2013.

27. Charmaz K. Constructing grounded theory: a practical guide through qualitative analysis. London; Thousand Oaks, CA: Sage Publications; 2006.

28. Task force on enhancing programs awareness to student clinician mental health and wellness. American Council of Academic Physical Therapy Web site. Available from: https://www. acapt.org/ [cited 2 November 2020]. 
29. Macauley K, Plummer L, Bemis C, et al. Prevalence and predictors of anxiety in healthcare professions students. Health Prof Educ (2018) 4(3): 176-85. doi: 10.1016/j.hpe.2018. 01.001

30. Commission on Accreditation of Physical Therapy Education. 2018-19 fact sheet: physical therapist education programs. Available from: http://www.capteonline.org/uploadedFiles/ CAPTEorg/About_CAPTE/Resources/Aggregate_Program_ Data/AggregateProgramData_PTPrograms.pdf\#search $=\%$ 22fact [updated 2019; cited 13 January 2020].

31. McCallum CA, Mosher PD, Howman J, et al. Development of regional core networks for the administration of physical therapist clinical education. J Phys Ther Educ (2014) 28. Available from: https://journals.lww.com/jopte/Fulltext/2014/00001/
Development_of_Regional_Core_Networks_for_the.8.aspx [cited 06 March 2020].

32. DeAngelis T. Practicing distance therapy, legally and ethically. Monitor Psychol (2012) 43(3): 52.

\section{*Bridget R. Eubanks}

Doctor of Physical Therapy Program

College of Pharmacy and Health Sciences

Campbell University

4150 US 421 South

Lillington, NC 27546

USA

Email:bripa@campbell.edu 


\section{Appendix A: Survey Questionnaire}

PART I: Demographics and Clinical Education Curricular

\section{Characteristics}

1. How many years have you been a DCE/ACCE?

- $<1$ years

- 1-3 years

- 4-6 years

- 7-10 years

- $>10$ years

2. Please select the description that best describes your institution:

- Public, Urban/Suburban

- Public, Rural

- Private, Urban/Surburban

- Private, Rural

3. Please select the geographic region of your institution:

- Northeast

- Mid-Atlantic

- Southeast

- South

- Midwest

- Southwest

- Mountain

- Northwest

- West

4. What is your average class/cohort size? (sliding scale response 0-130)

5. Please select the statement that best describes your student cohort:

- The majority of our students come to our program from in-state

- We have a mixed cohort of in-state and out-ofstate students

- The majority of our students come to our program from out-of-state

6. Please select the statement that best describes your student cohort:

- The majority of our students are "Traditional" students (e.g. entering your program directly from undergraduate)

- The majority of our students are "Non-Traditional" (e.g. entering after some time off following undergraduate; second career, etc.)

- We have a mixed cohort of "Traditional" and "Non-Traditional"
7. How many full-time non-ICE clinical experiences does your curriculum include? (sliding scale response 0-10)

8. Does your curriculum include full-time, non-ICE experiences before the didactic curriculum is complete?

- Yes

- No

9. If yes, what is the length of your first full-time clinical experience?

- 4 weeks

- 6 weeks

- 8 weeks

- 10 weeks

- 12 weeks

- Other

10. If yes, what is the length of your intermediate full-time clinical experience(s)?

- 4 weeks

- 6 weeks

- 8 weeks

- 10 weeks

- 12 weeks

- Other

11. How many terminal clinical experiences does your curriculum include?

- 1

- 2

- 3

- 4

- Other

12. What is the length of your terminal clinical experience(s)?

- 8 weeks

- 10 weeks

- 12 weeks

- 16 weeks

- Other

13. Do you require your students to go out of state for their full-time clinical experiences?

- Yes

- No

- We do not require this of students but do expect students to travel for clinical experiences if necessary to meet the requirements of the program 
14. If yes, for how many full-time clinical experiences are your students required to go out of state?

- 1

- $>1$

- All of them

15. On average, what percentage of your students complete at least one of their full time-clinical experiences within 1 hour of campus? (sliding scale response $0-100$ )

16. On average, what percentage of your students complete at least one of their full-time clinical experiences out of state? (sliding scale response $0-100)$

17. On average, what percentage of your students complete all of their full-time clinical experiences out of state? (sliding scale response $0-100$ )

18. What method do you use to match students to full-time clinical experiences?

- Lottery method (with student input)

- Computer match system (with student input)

- Lottery method without student input

- Computer match system without student input

- We match our full-time clinical experiences using either lottery or computer method depending on the level of rotation.

- Other

19. Do you have a policy that restricts where a student can complete a clinical experience if they have a disclosed medical or mental health diagnosis?

- Yes

- No

20. If yes, please describe your policy. [open ended response]

PART II: Institution Counseling and Psychological Support Services

21. To the best of your knowledge, what counseling and psychological support services are available to your students through your institution? (select all that apply)

- One-on-one counseling and support services

- Group counseling sessions

- Online/Skype or other video counseling services

- Online educational material

- Group classes

- Other

22. Does your faculty receive training on when and how to refer students to support services?

- Yes

- No

- Unsure

23. If yes, how is the training provided to faculty?

- During new-hire orientation

- Presentation to faculty during faculty meeting or other stand-alone meeting

- Through required online orientation modules

- Through online orientation modules that are not required

24. If no, how does your faculty learn about available counseling and psychological resources for students?

- Through emails and other online communications from institution

- Through a faculty liaison in our program/ department

- They don't.

25. Do your students receive specific information about available counseling and psychological support services offered at your institution?

- Yes

- No

- Unsure

26. If yes, when do the students receive information about counseling and psychological support services?

- At orientation only

- At orientation and annually during their time in the program

- As part of a class embedded in the curriculum

- Other

27. Do your students have access to your institution's counseling and psychological support services when they are away from campus during clinical experiences?

- Yes

- No

- Unsure 
28. If yes, what services are available to students when they are away from campus during clinical experiences? (select all that apply)

- Online visits with a provider

- Web-based resources

- Group therapy through online discussion boards

- Referral to providers in location student is currently living

- Other

PART III: Experiences and Perceptions of the DCE

29. In the past three years, have you been made aware of a student or students experiences a mental health concern during a full-time clinical experience?

- Yes

- No

30. If yes, how many students have you been made aware of?

- 1

- 2

- 3

- 4

- 5

- $>5$

31. If yes, did the student(s) reach out to you as the DCE to discuss concerns?

- Yes

- No

32. How did you find out that the student(s) were experience an issue?

- From the CI or SCCE

- From the student after the experience was over

- From another faculty member

- Other

33. What kinds of mental health concerns were the student(s) experiencing?

- Depression

- Anxiety

- Stress

- Other

34. What steps did you take to help support the students during the clinical experience? (select all that apply)

- Referred the student to institution counseling and support services

- Spoke with the student on the phone
- Did a site visit

- Involved the CI/SCCE (with student permission)

- Terminated the clinical experience early

35. Of the students who you were aware of experiencing mental health concerns during clinical experiences, how many were in placements more than 1 hour away from campus, including out of state?

- $100 \%$

- Approximately $75 \%$

- Approximately $50 \%$

- Approximately $25 \%$

- None. All of the students I have been involved with during these types of challenges have been at clinical sites within 1 hour of campus.

36. Of the students who have experience mental health concerns during a clinical experience, what level clinical experience were they in?

- All students were in first or intermediate fulltime clinical experiences

- All were in terminal clinical experiences

- Mixture of first, intermediate, and terminal clinical experiences

37. Of the students who experienced mental health concerns during a clinical experience, how many were unable to complete their rotation?

- $100 \%$

- Approximately $75 \%$

- Approximately $50 \%$

- Approximately $25 \%$

- None. All students successfully completed their clinical experience

38. From your perspective, have you noticed an increase in the number of students experiencing mental health concerns during full-time clinical education experiences?

- Yes

- No

- Unsure

39. Please describe mental health challenges you observe in students during clinical education experiences. If you have not had any experience with mental health concerns during clinical education then just write "none.": [open ended response]

40. What is the biggest challenge you face as the DCE in assisting and supporting students facing 
mental health concerns while on clinical rotations? [open ended response]

41. As the DCE, do you feel prepared to assist students with mental health concerns during their clinical education experiences?

- Yes

- No

- Unsure
42. If yes, what do you feel has prepared you the best to assist your students with mental health concerns during clinical education experiences? [open ended response]

43. If no, what would help you feel more prepared to assist students with mental health concerns during clinical education experiences? [open ended response] 